ORIGINAL ARTICLE

\title{
Frequency of Patients with Coronary Artery Disease Achieving Optimal Glycemic Control at Tertiary Care Hospital, Karachi
}

\author{
SHARAFUDDIN ${ }^{1}$, JAVED KHURSHED SHAIKH ${ }^{2}$, MUHAMMAD HASHIM KALWAR ${ }^{3}$, MUHAMMAD HASSAN BUTT ${ }^{4}$ \\ SARFRAZ HUSSAIN SAHITO ${ }^{5}$, MUHAMMAD RAFIQUE KANHAR ${ }^{6}$ \\ ${ }^{1}$ Clinical Fellow Cardiology, National Institute of Cardiovascular Diseases, Karachi \\ ${ }^{2,3,4}$ Assistant Professor Cardiology, National Institute of Cardiovascular Diseases, Sukkur \\ ${ }^{5,6}$ Senior Registrar Cardiology, National Institute of Cardiovascular Diseases, Khairpur \\ Corresponding author: Dr. Sharaf Uddin, Email: Sharf.dr@gmail.com, Contact: +923323104278
}

\begin{abstract}
Objective: To determine frequency of glycemic control in patients with coronary artery disease (CAD) visiting to National Institute of Cardiovascular Diseases, Karachi.

Study Design: Descriptive Cross-Sectional study

Place and Duration: This study was conducted at Department of Cardiology, National

Institute of Cardiovascular Diseases, Karachi, Pakistan for six months duration from $12^{\text {th }}$ October 2019 to $11^{\text {th }}$ April 2020.

Methodology: One hundred and ten patients of both gender with coronary artery disease were enrolled in this study. Informed consent was taken after explaining the procedure, risks and benefits of the study. In our study, all the included patients were given the emergency treatment and their blood samples were sent to laboratory to assess the outcome variable i.e. glycemic control. All the data was analyzed by SPSS 24.0.

Results: Mean \pm SD of age was $62.5 \pm 8.4$ years. Out of 110 patients, $65(59.1 \%)$ were male while $45(40.9 \%)$ were female. Obesity was found in 41 (37.3\%) patients. Glycemic control was noted in $20(18.2 \%)$ patients.

Conclusion: It is to be concluded that less glycemic control was noted among coronary artery disease (CAD) patients with increasing prevalence of diabetes. Indicators of quality care (HbA1c \& other complications) should be assessed regularly for better diabetes management.

Keywords: Glycemic Control, Coronary Artery Disease, Type 2 Diabetes, Risk Factors
\end{abstract}

\section{INTRODUCTION}

The leading cause of morbidity and mortality in patients with type 2 diabetes is cardiovascular disease (CVD) [1] "Holy grail" status has been given to glucose control as it relates to CVD risk in clinical diabetes. DM has reached epidemic proportions over the world, and its incidence is on the rise [2]. DMD diagnosis has the same serious consequences as CHD diagnosis (CAD). A history of myocardial infarction (MI) and diabetes both increase cardiovascular mortality in all age categories and for both sexes, and the two are profoundly synergistic [3]. Die Diabetes mellitus (DM) is connected with an elevated mortality risk of 2 to 4 times from heart disease. Most patients with diabetes over the age of 65 will die from heart disease or a stroke. In addition, patients with diabetes mellitus have a higher mortality rate after a $\mathrm{Ml}$, and their long-term prognosis is worse with CAD [4].

More than half of the world's diabetics live in Asia, where there are 72 million diabetics in Southeast Asia (compared to 24 million in the United States and 56 million in Europe) and where diabetes is on the rise more rapidly than anywhere else [5]. According to the International Diabetes Federation (IDF), Pakistan has an estimated 6.9 million diabetics, and this figure is anticipated to rise to 14.4 million by 2040 [6]. World Health Organization (WHO) standards for Baluchistan provinces indicate a diabetes prevalence of 8.6 percent, 11.1 percent, and 13.9 percent. NWFP and Sindh, respectively [7]. Although the prevalence of heart failure in Asia is poorly understood, there are also limited data on the frequency of diabetes in Southeast Asian patients with heart failure, its association with clinical variables, and its effect on the prognosis of these patients.
In fact, decreased glucose tolerance and impaired fasting glucose have been linked to macrovascular disease [6] and a higher mortality rate [7]. Many patients with acute coronary syndrome are diabetic. Diabetes mellitus can be related with glucose intolerance, although not impaired fasting glucose [8]. Hyperglycemia can have adverse effects due to both glucose and insulin levels. Reactive oxygen species are elevated, and advanced glycation products are formed [9]. Smooth muscle cells in the vascular system have been found to be mitogenic when hyperinsulinemia is present [9]. Being that elevated blood glucose is a frequent and possibly curable illness, it is of special clinical importance to determine whether elevated blood glucose contributes to CAD.

Maintaining stringent glycemic control in individuals with coronary artery disease relies heavily on compliance with anti-Diabetic treatments like oral hypoglycemic agents and insulin. The study by Akhter et al. found that only $16.6 \%$ of patients had satisfactory glucose control. Patients with coronary artery disease participated in this study to determine the degree of glycemic control they had. Diabetes and cardiovascular disease are on the rise in our region of the world. Majority of our people does not take diabetes seriously due to low socioeconomic situations and lack of awareness of the dangers of uncontrolled diabetes, which leads to earlier onset of cardiovascular disease and worse outcomes. Uncontrolled diabetes is becoming more and more of a social concern. Additionally, the results of this study will be published and shared with other health care professionals and government officials in order to establish measures to combat this silent killer. - These patients are already at high risk for diabetes, and this study 
will raise their awareness of the importance of regular diabetes monitoring.

\section{MATERIALS AND METHODS}

This descriptive/cross-sectional study was conducted at Department of Cardiology, National Institute of Cardiovascular Diseases, Karachi Pakistan for six months duration from $12^{\text {th }}$ October 2019 to $11^{\text {th }}$ April 2020.

Total 110 diabetic patients with coronary artery disease of either gender were enrolled in this study. Patients' ages were ranging between 40 to 80 years. An informed consent was taken from the patient or his/her next kin at the time of admission. Patients on steroids, decompensated liver disease and pancreatic disease patients were excluded.

Emergency treatment was given, blood sample was sent to laboratory to assess the outcome variable i.e. glycemic control in accordance with operational definition. All the procedure was performed by researcher himself under the supervision of consultant $>5$ years of experience. Data was recorded into a predesigned proforma. Confounding or explanatory variables and biasness were controlled by strictly following inclusion and exclusion criteria.

Data was analyzed by SPSS version 24.0. Mean \pm Standard deviation was calculated for age and duration of diabetes. Frequency and percentage were calculated for gender, smoking status, obesity, and outcome variable i.e. glycemic control (yes/no). Selection of sample size was restricted to selection criteria and to control the explanatory variables /confounders or effect modifiers stratification was done on age, duration of diabetes, gender, obesity and smoking status to see the impact of these on outcome by using chi-square test consider $\mathrm{P}<0.05$ as significant.

\section{RESULTS}

Mean \pm SD of age was $62.5 \pm 8.4$ with C.I (60.91-.64.08) years. Mean \pm SD of duration was $7.3 \pm 2.8$ with C.I (6.777.82 ) years. Out of 110 patients, 65 (59.1\%) were male while $45(40.9 \%)$ were female. Smoking status showed that $46(41.8 \%)$ patients were smokers. Obesity was found in $41(37.3 \%)$ patients. (Table 1$)$

Table No 1: Baseline Details of all the patients

\begin{tabular}{|l|l|l|}
\hline Variables & Frequency No. & \%age \\
\hline Mean Age (Years) & $62.5 \pm 8.4$ & - \\
\hline Mean Duration (yrs) & $7.3 \pm 2.8$ & - \\
\hline Gender & 65 & $59.10 \%$ \\
\hline Male & 45 & $40.90 \%$ \\
\hline Female & $41.80 \%$ \\
\hline Smoking Status & 46 & $58.18 \%$ \\
\hline Yes & 64 & $37.30 \%$ \\
\hline No & 41 & $62.73 \%$ \\
\hline Obesity & 69 & \\
\hline Yes &
\end{tabular}

Glycemic control was noted in $20(18.2 \%)$ patients while $90(82.8 \%)$ patients had no glycemic control. (Figure 1)

Stratification of age group, gender, duration of diabetes, and obesity was done with respect to glycemic control and found no significant difference i.e. $(P \geq 0.05)$. Table 2-5

Figure No 1: Frequency of Glycemic control among all the patients

\section{Glycemic Control}

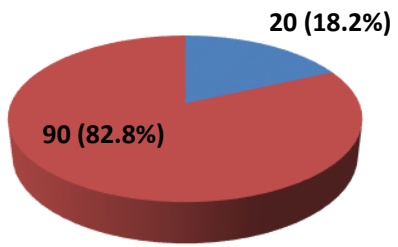

Yes

No

Table 2: Stratification of Age Group With Glycemic Control

\begin{tabular}{|c|c|c|c|}
\hline \multirow{2}{*}{$\begin{array}{l}\text { Age Group [in } \\
\text { years] }\end{array}$} & \multicolumn{2}{|c|}{ Glycemic control } & \multirow{2}{*}{ P-value } \\
\hline & \multirow{2}{*}{ YES } & \multirow{2}{*}{ NO } & \\
\hline & & & \\
\hline \multirow{3}{*}{$40-60$} & 12 & 58 & \\
\hline & $(10.9 \%)$ & \multirow[t]{2}{*}{$(52.7 \%)$} & \\
\hline & & & \multirow[t]{2}{*}{0.709} \\
\hline \multirow[t]{2}{*}{$>60$} & 8 & 32 & \\
\hline & \multirow[t]{2}{*}{$(7.3 \%)$} & \multirow[t]{2}{*}{$(29.1 \%)$} & \\
\hline & & & \\
\hline
\end{tabular}

Table 3: Stratification of Gender with Glycemic Control

\begin{tabular}{|c|c|c|c|}
\hline \multirow[t]{2}{*}{ GENDER } & \multicolumn{2}{|c|}{ GLYCEMIC CONTROL } & \multirow[t]{2}{*}{ P-VALUE } \\
\hline & \multirow{2}{*}{ YES } & \multirow{2}{*}{$\mathrm{NO}$} & \\
\hline & & & \\
\hline \multirow[t]{3}{*}{ MALE } & 11 & 54 & \\
\hline & $(10.0 \%)$ & $(49.1 \%)$ & \\
\hline & & & 0.220 \\
\hline \multirow[t]{2}{*}{ FEMALE } & 9 & 36 & \\
\hline & \multirow[t]{2}{*}{$(8.2 \%)$} & \multirow[t]{2}{*}{$(32.7 \%)$} & \\
\hline & & & \\
\hline
\end{tabular}

Table 4: Stratification Of Duration With Glycemic Control

\begin{tabular}{|c|c|c|c|}
\hline \multirow{2}{*}{$\begin{array}{l}\text { DURATION [In } \\
\text { Years] }\end{array}$} & \multicolumn{2}{|c|}{ GLYCEMIC CONTROL } & \multirow[t]{2}{*}{ P-VALUE } \\
\hline & YES & \multirow{2}{*}{ NO } & \\
\hline & & & \\
\hline \multirow[t]{3}{*}{$1-6$} & 9 & 49 & \\
\hline & \multirow[t]{2}{*}{$(8.2 \%)$} & \multirow[t]{2}{*}{$(44.5 \%)$} & \\
\hline & & & 0444 \\
\hline \multirow[t]{2}{*}{$>6$} & 11 & 41 & \\
\hline & \multirow[t]{2}{*}{$(10.0 \%)$} & \multirow[t]{2}{*}{$(37.3 \%)$} & \\
\hline & & & \\
\hline
\end{tabular}


Table 5: Stratification of Obesity with Glycemic Control

\begin{tabular}{|c|c|c|c|}
\hline \multirow[t]{2}{*}{ OBESITY } & \multicolumn{2}{|c|}{ GLYCEMIC CONTROL } & \multirow[t]{2}{*}{ P-VALUE } \\
\hline & \multirow{2}{*}{ YES } & \multirow{2}{*}{$\mathrm{NO}$} & \\
\hline & & & \\
\hline \multirow[t]{3}{*}{ OBESE } & 8 & 33 & \\
\hline & $(7.3 \%)$ & $(30.0 \%)$ & \\
\hline & & & \multirow[t]{2}{*}{0.780} \\
\hline \multirow[t]{2}{*}{ NON-OBESE } & 12 & 57 & \\
\hline & \multirow[t]{2}{*}{$(10.9 \%)$} & \multirow[t]{2}{*}{$(51.8 \%)$} & \\
\hline & & & \\
\hline
\end{tabular}

\section{DISCUSSION}

These findings are presented in connection to various clinical indicators in patients with coronary artery disease who are being treated at an urban tertiary care hospital located in Pakistan's largest metropolis. Clearly, our population has a big number of diabetics who are not under ideal control, putting a tremendous strain on our health care system and economy.

Younger age, greater diabetes duration, and high triglyceride levels were all related with poor glucose management $[11,12]$.

Many people with diabetes have macrovascular disease in the form of coronary heart disease, which is the leading cause of death. In individuals with poor glycemic control, both micro and macrovasculopathies were more common.

A considerable percentage of patients arriving to our hospital were fat, and this study illustrates the growing incidence of obesity in Pakistani society. They were mostly in the 40-55 age bracket, which raises the risk of developing diabetes, high blood pressure and lipid disorders during the most productive years of life, creating a financial cost to both individuals and society.

There were no exceptions. All patients with poor glycemic control also suffered from poorly-controlled blood pressure and cholesterol, which indicated that the whole treatment was inadequate and that other measures were not well-contained. Intriguingly, ADA-recommended objectives for lipids and blood pressure were not met by patients who had optimum glycemic control.

Since these are typical modifiable risk factors that, if left unaddressed, can lead to early start of coronary heart disease, this discovery is of particular concern to South Asians. The causes for this could be complex. It could be due to financial constraints, as the patient must pay for these prescriptions out of pocket themselves. In addition, clinicians may not adhere to treatment guidelines.

In this investigation, we found that asymptomatic DM2 patients with the worst glycemic control had increased CAD severity, as measured by a higher frequency of CAD and plaque features associated with possible plaque instability.

Due to some particular characteristics of this group, it can be difficult to diagnose CAD in individuals with DM2. Diabetes-related sensory autonomic neuropathy affects myocardial cells, resulting in a higher risk of acute infarct myocardial silent [13]. DM2 atherosclerotic coronary alterations were evaluated in the majority of research [14,
15] using patients with diverse glycemic control, disease duration, and risk factor characteristics. Asymptomatic DM2 patients were divided into groups based on their glucose management, with no significant differences in other cardiovascular risk factors frequently linked with diabetes. For example, in our sample of 110 people, fasting glucose, glycated hemoglobin, insulin and sulfonylurea use, and longer disease duration were related with higher cardiovascular risk [16-19].

In diabetic individuals with severe CAD, a substantial risk of acute coronary events should be acknowledged, according to Choi's study [20].

The findings of our study are comparable with multiple studies conducted by various researchers worldwide, few of which are discussed below.In our study, the mean age was noted as $62.5 \pm 8.4$ years. In a study done by Akhter J, et al. [10] the mean age was reported as $53.1 \pm 11.9$ years. Another study of Nielson C, et al [21], reported the mean age as $54.4 \pm 13.3$ years. Grenier J, et al [22] in his study reported the mean age as 62 years whereas Lemesle $G$, et al [23] stated the mean age of patients as $67 \pm 10$ years. Also another study conducted by Tavares CA, et al [24] reported the mean age as $53.8 \pm 6$ years.

In this study, the mean duration was found as $7.3 \pm 2.8$ years. Akhter J, et al. [10] also reported the mean duration as 7.6 years.In present study, out of 110 patients, 65 $(59.1 \%)$ were male while $45(40.9 \%)$ were female.Akhter J, et al. [10] in his study reported that $51.8 \%$ patients were male while $28.2 \%$ were female. Lemesle $G$, et al [23] also stated that $156(28 \%)$ were females in his study. Another study done by Tavares $\mathrm{CA}$, et al [24] reported that males were $34(37.8 \%)$.

In current study, smoking status showed that 46 $(41.8 \%)$ patients were smoker.Akhter J, et al. [10] noted the prevalence of smoking in $9.8 \%$ patients while Nielson $\mathrm{C}$, et al [21], reported smoking prevalence in $42 \%$ patients and Grenier J, et al [22] noted prevalence in $10.1 \%$ patients. Lemesle G, et al [23] stated that 69 (13\%) were found as smokers ad Tavares CA, et al [24] reported that 18 (20\%) were smokers.

In our study, obesity was found in 41 (37.3\%) patients. Tavares CA, et al [24] noted obesity in 28 (31.1\%) patients. In this study, glucose control was observed in 20 participants (18.2\%). Akhter J, et al. [10] reported that $52.9 \%$ of patients had glycemic control. The occurrence of CAD was associated with poor glycemic control, smoking, and obesity. All of these parameters - especially glycemic control - have never been studied in a controlled way before, as they were in our study.

\section{CONCLUSION}

In conclusion, coronary artery disease (CAD) patients with diabetes had less glycemic control, and the care offered at the primary level needs to be improved because most people cannot afford the cost of complications. To offer diabetics with cost-effective care, the government and various non-governmental groups should invest in polyclinics in different places. For optimal diabetes management, $\mathrm{HbA1c}$ and other problems should be monitored on a frequent basis. To increase the quality of care offered to diabetics, patient registers should be implemented nationwide. 


\section{REFERENCES}

1. CDC (Accesses February 2012] National Diabetes Fact Sheet. 2011. Available www.cdc.gov/diabetes/pubs/pdf/ndfs 2011.pdf

2. GO AS, Mozaffarian D, Roger VI Benjamin EJ, Berry JD, Blaha MJ, et al. Heart Disease and Stroke Statistics - 2014 Update: AHA. 2014;129(3):399-410.

3. Nusca A, Tuccinardi D, Albano M, Cavallaro C, Ricottini E, Manfrini S, et al. Glycemic variability in the development of cardiovascular complications in diabetes.et al. Glycemic variability in the development of cardiovascular complicationsin diabetes. Diabetes Metab Res Rev. 2018;34(8):e3047.

4. Aronson D, Edelman ER. Coronary artery disease and diabetes mellitus. Cardiol Clin. 2014;32(3):439-55.

5. DF Diabetes Atlas Group. Update of mortality attributable to diabetes for the IDF Diabetes Atlas: Estimates for the year 2013. Diabetes Res Clin Pract 2015;109:461-5.

6. Tavares CA, Rassi CH, Fahel MG, Wajchenberg BL, Rochitte CE, Lerario AC. Relationship between glycemic control and coronary artery disease severity, prevalence and plaque characteristics by computed tomography coronary angiography in asymptomatic type 2 diabetic patients. Int $\mathrm{J}$ Cardiovasc Imaging. 2016;32(10):1577-85

7. Basit A, Hydrie MZ, Hakeem R, Ahmedani MY, Waseem M. Glycemic control, hypertension and chronic complications in type 2 diabetic subjects attending a tertiary care centre. J Ayub Med Coll Abbottabad. 2005;17(2).

8. Nielson C, Lange T, Hadjokas N. blood glucose and coronary artery disease in nondiabetic patients. Diabetes Care. 2006 May 1;29(5):998-1001.

9. Li G, Zhang P, Wang J, An Y, Gong a, Gregg EW, et al. Cardiovascular mortality, all-cause mortality, and diabetes incidence after lifestyle intervention for people with impaired glucose tolerance in the Da Qing Diabetes Prevention Study: a 23-year follow-up study. Lancet Diabetes Endocrinol. 2014;2(6):474-80

10. Akhter J. Patterns, control and complications of diabetes from a hospital based registry established in a low-income country. BMC Endocr Disord. 2017;17(1):30.

11. von Hurst PR, Stonehouse W, Coad J. Vitamin D supplementation reduces insulin resistance in South Asian women living in New Zealand who are insulin resistant and vitamin $\mathrm{D}$ deficient - a randomised, placebo-controlled trial. Br J Nutr. 2010;103(4):549- 55.

12. Kositsawat J, Freeman VL, Gerber BS, Geraci S. Association of A1C levels with vitamin D status in U.S. adults: data from the National Health and Nutrition Examination Survey. Diab Care. 2010;33(6):1236-8

13. Barthelemy O, Lê Feuvre C, Timsit J (2007) Silent myocardial ischemia screening in patients with diabetes mellitus. Arq Bras Endocrinol Metabol 51:285-93.
14. Motoyama S, Kondo T, Sarai M et al (2007) Multislice computed tomographic characteristics of coronary lesions in acute coronary syndromes. J Am Coll Cardiol 50:319-26.

15. Motoyama S, Sarai M, Harigaya H et al (2009) Computed tomographic angiography characteristics of atherosclerotic plaques subsequently resulting in acute coronary syndrome. J Am Coll Cardiol 54:49-57.

16. Rana JS, Dunning A, Achenbach S et al (2012) Differences in prevalence, extent, severity and prognosis of coronary artery disease among patients with and without diabetes undergoing coronary computed tomography angiography. Diabetes Care 35:1787-1794

17. Kwon YS, Jang JS, Lee CW et al (2010) Comparison of plaque composition in diabetic and non-diabetic patients with coronary disease using multislice CT angiography. Korean Circ J 40:581-88.

18. Raggi P, Shaw LJ, Berman DS, Callister TQ (2004) Prognostic value of coronary artery calcium screening in subjects with and without diabetes. J Am Coll Cardiol 43:1663-69.

19. Qu W, Le TT, Azen SP et al (2003) Value of coronary artery calcium scanning by computed tomography for predicting coronary heart disease in diabetic subjects. Diabetes Care 26:905-10.

20. Choi EK, Chun EJ, Choi S et al (2009) Assessment of subclinical coronary atherosclerosis in asymptomatic patients with type 2 diabetes mellitus with single photon emission computed tomography and coronary computed tomography angiography. Am J Cardiol 104:890-96.

21. Nielson C, Lange T, Hadjokas N. Blood glucose and coronary artery disease in nondiabetic patients. Diab Care. 2006;29(5):998-1001.

22. Grenier J, Leiter LA, Langer A, Goldin L, Teoh H, Connelly $\mathrm{KA}$, et al. Glycaemic control and cardiovascular risk factor management in patients with diabetes with and without coronary artery disease: Insights from the diabetes mellitus status in Canada survey. Eur Heart J-Qual Care Clin Outcomes. 2016;2(4):277-84.

23. Lemesle G, Meurice T, Tricot O, Lamblin N, Bauters C. Association of diabetic status and glycemic control with ischemic and bleeding outcomes in patients with stable coronary artery disease: the 5 -Year CORONOR registry. $J$ Am Heart Assoc. 2018;7(10):e008354

24. Tavares CA, Rassi CH, Fahel MG, Wajchenberg BL, Rochitte CE, Lerario AC. Relationship between glycemic control and coronary artery disease severity, prevalence and plaque characteristics by computed tomography coronary angiography in asymptomatic type 2 diabetic patients. Int $\mathrm{J}$ Cardiovasc Imaging. 2016;32(10):1577-85. 